\title{
As Geociências e as Tecnologias de Informação e Comunicação (TICs) na interface Ensinar-Aprender
}

\author{
Vlander Verdade Signoretti \\ Instituto Federal de Educação, Ciência e \\ Tecnologia do Sul de Minas Gerais - Câmpus \\ Pouso Alegre. \\ vlandervs@gmail.com \\ Celso Dal Ré Carneiro \\ Instituto de Geociências, Universidade Esta- \\ dual de Campinas, Campinas, SP. \\ cedrec@ige.unicamp.br
}

\begin{abstract}
GEOSCIENCES AND INFORMATION AND CoMmuniCATION TECHNOLOGIES (ICTS) IN the TEACHING-LEARNING INTERFACE. INFORMATION Information technology and communication (ICT), supported by the knowledge on Geosciences, can help to change the attitude of teachers and students of basic education. It may also improve the performance of students on some assessment learning tests of science teaching, a specific area which accumulates many critical results. This article proposes that educational models supported in Geosciences can contribute to meaningful learning and to encourage teachers to create situations favorable to learning. Innovative solutions and approaches are required for increasingly support training courses for teachers, guided by computers, to integrate ICT in education for students. It is concluded that investing in education implies, besides the creation of real and virtual spaces of communication, continuous education and appreciation of those who promote their development. Science education, and hence Geosciences teaching, represents the generation of conditions for forming cult citizens, able to discern properly among choices that will face them along all their life.Citation: Signoretti V.V., Carneiro C.D.R. 2014. As TIC's no ensino de Geociências: por uma inovaçãa na interface entre ensinar e aprender. Terræ Didatica, 10(3):466-473. http://www.ige.unicamp.br/terraedidatica/.
\end{abstract}

KEYWORDS : Geosciences teaching, ICT in education, teacher training.

RESUMO As tecnologias de informação e comunicação (TICs), apoiadas em conhecimentos de Geociências, podem contribuir para mudar a postura de professores e alunos da educaşão básica e melhorar o desempenho de alunos nos exames de avaliação de aprendizado. Na área de ensino de Ciências, os resultados têm sido preocupantes e até mesmo críticos. Este artigo propõe que modelos educacionais apoiados em Geociências e condizentes com a época atual possam contribuir para a aprendizagem significativa e para estimular o professor a criar situações favoráveis ao aprendizado. Exigem-se soluções inovadoras e abordagens que fundamentem, cada vez mais, cursos de formação de professores, pautados em computadores, para integrar as TICs à educação do aluno. Conclui-se que investir em educação nessa época de imprevisibilidade pressupõe, além da criação de espaços reais e virtuais de comunicação, formação contínua e valorização daqueles que promovem o seu desenvolvimento. O ensino de Ciências e, conseguinte, o ensino das Geociências, representa a geração de condições para formação de cidadãos cultos e capazes de discernir de modo adequado frente às escolhas que a vida se thes apresentará

PALAVRAS-CHAVE: Ensino de Geociências, TICs no ensino, Formação de professores. 


\section{Introdução}

A função docente tem sofrido transformações significativas no Brasil, tanto em relação às demandas colocadas nas mãos dos professores, quanto devido ao cenário de mudança que permeia o tecido social. Como resultado, vive-se período de rápido e constante avanço tecnológico que interfere na prática pedagógica e influencia o processo de ensino e aprendizagem (Debald 2012). Grande parte das pressões deve-se ao fato de as Tecnologias de Informação e Comunicação (TICs) serem assimiladas mais rapidamente pelas crianças e jovens do que pelas escolas, pelo ambiente escolar e pelos próprios professores.

Nas escolas, em um movimento paralelo, muitos gestores fazem grandes investimentos para criar laboratórios de ensino informatizado dotados de recursos da Internet. Entretanto, o resultado de sucessivas edições de exames de avaliação de aprendizado na área de ensino de Ciências, de abrangência nacional e internacional (como o PISA, sigla em inglês para "Programa Internacional de Avaliação de Estudantes”), reforça a impressão de que o nível de insucesso escolar superou o patamar preocupante e tornou-se crítico. Embora mediante uso de computadores seja possível compor ambientes favoráveis à aprendizagem significativa e aproveitar no ensino o alto grau de interação que cada computador oferece, o desempenho dos estudantes brasileiros continua a ser medíocre. Em verdade, uma falsa solução é colocada em prática, até mesmo porque ainda não surgiu solução adequada para o problema.

A repetição de resultados negativos sugere que os requisitos básicos que garantem excelência no ensino não repousam, em definitivo, na infraestrutura de sala de aula, mas na capacitação do professor. Os caminhos para superação do impasse distanciam-se do investimento em recursos materiais e se aproximam de fatores menos tangíveis, como capacitação docente.

Talvez devêssemos seguir a pista de que "o foco não está nas máquinas, mas nas pessoas” (Neves 2009:26).

A preocupação com a formação docente emergiu sobretudo a partir dos anos 1990 (Debald 2012), ou seja, a temática da formação docente no Brasil é relativamente recente quando comparada com outros países, principalmente os europeus. Isso se deve à existência de políticas que priorizavam o ensino (Debald op. cit.). Desde então, o interesse por questões relacionadas à formação inicial docen- te e oferta de cursos de atualização e capacitação tem tido crescimento exponencial.

Martins e Carneiro (2014a) assinalam que o ensino de Geociências pode contribuir para melhorar o quadro de formação docente, na medida em que fornece uma visão de conjunto do funcionamento do Sistema Terra e ajuda a entender a complexa dinâmica do planeta (Martins e Carneiro 2012). Professores formados sob esse enfoque podem contribuir para o processo de formação conceitual de seus alunos, pondo em prática a conceitualização, que é um "processo dinâmico que ocorre nas mentes dos indivíduos, como resultado de interações socialmente situadas com eventos e experiências externas" (Mortimer et al. 2011).

O presente artigo pretende examinar algumas propostas e modelos educacionais que nos parecem adequados e condizentes com a época atual, com a dupla finalidade de estimular o professor a criar situações favoráveis ao aprendizado e incentivar a utilização de conceitos ligados ao campo das Geociências para proporcionar aprendizagem significativa.

\section{Motivar, criar significado e, enfim... promover aprendizagem}

A aprendizagem significativa (como concepção de Ausubel, apud Moreira e Masini 1982) é uma teoria que valoriza os conhecimentos prévios dos alunos, tendo como premissa a concepção de que cada nova informação é assimilada na estrutura cognitiva desde que se forme uma conexão com os conceitos anteriormente elaborados. Isso determina que o armazenamento de informações no cérebro humano seja muito organizado, segundo uma teia hierárquica conceitual responsável pela união de elementos mais específicos a conceitos mais gerais (Moreira e Masini 1982).

A melhoria dos índices de sucesso escolar no Brasil, principalmente em ciências, depende fundamentalmente do trabalho do professor/educador. Signoretti e Carneiro (2013:1557) apontam a necessidade de se compatibilizar, por parte de alunos e professores, o espírito de cooperação e interatividade que os TICs oferecem com uma nova concepção de escola e de construção do conhecimento. Deve-se conciliar certos elementos básicos do ambiente escolar como por exemplo produzir situações de aprendizagem condizentes com a expectativa de alunos motivados e dispostos a aprender. Ao mes- 
mo tempo, é necessário valorizar os professores reflexivos, preparados e comprometidos, prontos para dialogar com seus alunos.

O professor é um gestor em sua sala de aula. Ele motiva, lidera, planeja, organiza, negocia, define tempo, conteúdos, pré-requisitos, abordagens, estratégias metodológicas, tecnologias e processos de avaliação. Ao educar com TICs, todas essas atividades se renovam e ampliam o papel do professor (Neves 2009:20).

É preciso que o professor esteja apto a construir um ambiente educacional que leve em conta "os conhecimentos prévios dos alunos, seus interesses, suas expectativas e oportunizando-lhes novas descobertas" (Signoretti e Carneiro 2013:1566). Para que a mudança seja bem sucedida, tanto o aluno quanto o professor precisam conhecer e saber lidar, agir e interagir com os recursos tecnológicos contemporâneos.

O ensinar e o aprender compartilham caminhos. Caminhar lado a lado, porque professor e aluno se conhecem, comunicam-se, interagem. Mais do que a pretensão de 'ensinar' conteúdos é conhecer as expectativas do aluno em alcançá-los, fornecendo-lhe pistas, motivando, compartilhando do processo de construção do seu conhecimento, para que o aluno dele possa fazer uso em situações e ou ações de vida e, assim, de forma subjetiva, transformando-o (Signoretti e Carneiro 2013:1565).

O educador que assume a responsabilidade de ministrar os saberes de ciência precisa buscar autonomia intelectual de tal modo que se torne capaz de propiciar um ensino que dê sentido à aprendizagem do aluno e:

(...) levar seus alunos a compreender, com maior exatidão, as relações de poder existentes entre as ciências e a sociedade, de modo a capacitá-los a lutar por seus ideais e pelo atendimento pleno de suas demandas, e tornando-os cidadãos autônomos, éticos e responsáveis (Martins e Carneiro 2014a).

\section{0 universo das TICS}

Barreto et al. (2006), em levantamento abrangente de teses e dissertações (T\&D) sobre educação e tecnologia, com ênfase nas TICs, observam que muitas tecnologias vinculadas ao ensino presencial - e tão profundamente apropriadas pela escola que têm sido chamadas simplesmente de "educacio- nais" - "foram simplesmente descartadas, apagadas e substituídas pela informática, pelos multimeios e pelas novas mídias, em nome da atratividade e da interatividade". Prosseguem as autoras

Em geral, as chamadas novas tecnologias são associadas a mudanças estruturais e, ao mesmo tempo, desvinculadas das condições materiais dos contextos educacionais, mesmo quando a EAD é defendida como única alternativa de acesso às TICs (Barreto et al. 2006:37).

A pesquisa permitiu identificar duas tendências, que Barreto et al. (2006) associam de um lado com o ensino presencial e de outro com o ensino virtual ou em processo de virtualização (como a educação a distância ${ }^{1}$, por exemplo)

$\mathrm{Na}$ tentativa de sistematizar as duas tendências, é possível afirmar que a referida ao ensino presencial propõe: o redimensionamento do ensino presencial, sem mencionar outro lugar ou modalidade que extrapole as instituições educativas regulares; o investimento na interação professor-aluno, seja na perspectiva afetiva, seja na do compartilhamento da objetividade social; e o fortalecimento do binômio ensino-aprendizagem. Em contrapartida, a tendência à virtualização aponta para: o deslocamento da dimensão presencial para a virtual; uma nova relação educativa na comunidade virtual, estabelecida de "modo espontâneo", rompendo com a assimetria presente na escola; e a quebra do binômio ensino-aprendizagem, privilegiando apenas o segundo elemento do par, pensado como “auto-aprendizagem”.(Barreto et al. 2006, p.38).

\section{Obsolescência... A escola, por acaso, tornou- se obsoleta?}

A ciência e a tecnologia tornaram-se forças produtivas na medida em que se gerou um quadro de mudança constante a partir da produção acelerada de conhecimentos científicos, inovações tecnológicas, informação e comunicação. $\mathrm{O}$ conhecimento transformou-se na força motriz da produção. Diferentes proposições educacionais que têm sido apresentadas induzem à necessidade de se redimensionar o ensino de ciência face às exigências $\mathrm{da}$ realidade e permitem repensar a prática pedagógica. A escola parece ter se tornado obsoleta. Muitos autores argumentam que sim,

1 A expressão Educação a Distância tem sido referida normalmente pela sigla $\mathrm{EaD}$, enquanto alguns autores propõem que EAD signifique Educação Aberta à Distância, como Santos (2006). 
outros que não. Em certos casos, parece indiscutível que a escola tradicional tenha se mantido distante das preocupações centrais que rodeiam o debate contemporâneo sobre educação.

Obsolescência é um fenômeno industrial e mercadológico que antecede os anos 1940 e se acentuou após a Segunda Guerra Mundial; sustenta-se na expectativa de curta duração de um produto qualquer. Pelo menos duas vertentes são reconhecidas - a obsolescência planejada e a percebida. A obsolescência planejada decorre de decisões industriais e empresariais que se aproveitam da existência de, ou induzem, um desgaste anormal do produto, de tal modo que isso obriga o detentor do bem a substituí-lo, apenas para continuar a usufruir do benefício que o produto lhe oferece. A obsolescência perceptiva transforma a aparência das coisas, como nos ditames da moda, em que algum bem útil rapidamente se torna obsoleto, de modo a abrir espaço para outros bens que incluam algum tipo de novidade, não necessariamente alguma inovação. Aos poucos, as duas modalidades tornaram-se tão amplamente disseminadas, que a sociedade parece ter-se tornado desprovida de "fronteiras e barreiras" (Silva 2012).

E a escola, permaneceu inalterada nesse contexto? Tornou-se obsoleta? Quais os desafios? Reunião de uma Comissão Internacional sobre Educação para o séculoXXI promovida pela Unesco em Paris resultou em dois relatórios. O primeiro foi organizado por Jacques Delors $(1996,2005)$ que reconhece quatro pilares básicos do processo educacional: Aprender a Conhecer (ou Aprender a Aprender), Aprender a Fazer, Aprender a Viver Juntos e Aprender a Ser. Fialho (2002b) adiciona a estes o Aprender a Sentir. O segundo relatório foi organizado por Edgar Morin (2000, 2001), que aponta os sete saberes necessários à educação do futuro (Cegueira Paradigmática, Conhecimento Pertinente, Ensino da Condição Humana, Ensino das Incertezas, Identidade Terrena, Ensino da Compreensão Humana e a Ética do Gênero Humano), explicitados do seguinte modo:

A natureza do conhecimento humano: preparar o indivíduo para o risco do permanente erro e da ilusão; O conhecimento pertinente: superar a fragmentação e desenvolver aptidões individuais; A condição humana: por em evidencia o elo indissolúvel; $\mathrm{O}$ destino comum dos homens no planeta; $\mathrm{O}$ caráter da aventura humano: aprender a navegar entre ilhas de certeza, enfrentando o imprevisto e o inesperado; O essencial nas relações humanas: desenvolver a compreensão mútua. A ética da democracia e da cidadania: desenvolver a autonomia individual.
Maia (2003) utiliza o modelo apresentado por Fialho (2002b), que associa as propostas de Delors (1996) e Morin (2000) para desenvolver os sete saberes (Tab. 1). O modelo é denominado "Propostas para a Escola do Futuro" (Fialho 2002a, b).

Maia (2003) afirma que a escola tradicional não desenvolve a dimensão do Aprender a Aprender, sendo esta uma dimensão típica da Nova Escola (denominação que não guarda qualquer relação com o movimento escolanovista de Anísio Teixeira), cuja principal característica é não temer a inovação. A oferta de ensino compartimentado, descontextualizado e excessivamente abstrato, em uma etapa da vida em que a criança é muito ligada ao seu ambiente e à realidade circundante conduz a um argumento relevante sobre obsolescência da escola, na medida em que seria desejável partir do conhecimento que as crianças possuem, para transformá-lo em conhecimento científico e "reconstruindo sua realidade dentro do contexto dos novos conhecimentos" (Fracalanza 1986, p.11).

\section{Geociências no ensino fundamental}

Em uma sociedade cientificamente instruída, democrática e aberta, a Educação Básica deve permitir que todo e qualquer cidadão desenvolva conhecimentos e hábitos de pensamento básicos (AAAS 1989). Além disso, é preciso sensibilizar as novas gerações e incutir-lhes atitudes solidárias e humanistas (Domingo e Sequeiros 1998), que favoreçam a formação de uma visão menos utilitarista e predatória sobre a vida na Terra. Tem sido bem aceito que, para tomar decisões responsáveis, a população em geral deveria entender melhor alguns temas científicos nos quais se investem enormes somas de recursos em pesquisa e que envolvem cientistas de todo o mundo (Sgarbi 2001). Conhecimentos de Geociências são necessários para atingir tal compreensão:

Nos dias atuais, domesticamos não só os rios e ciclos hidrológicos, mas também os solos, as florestas e os animais, as bactérias, as montanhas, os pólos e os mares; alcançamos, ainda, a Lua, os mais profundos abismos oceânicos, deciframos o centro da Terra e enviamos artefatos para Marte, Júpiter, Saturno e, até mesmo, para além do Sistema Solar. [...] Estranhamente nos dias de hoje civilizar, isto é, desenvolver e progredir, não significa mais domesticar rios, mas sim contaminar a água, a atmosfera e destruir os ecossistemas, a base da vida. (Menegat e Carraro 2009, p.80-82). 
Tabela 1. Propostas para a Escola do Futuro. Fonte: baseada em Fialho (2002a, b)

\begin{tabular}{c|c|c}
\hline Delors & Escola do Futuro & Morin \\
\hline $\begin{array}{c}\text { Aprender a Aprender: adquirir os instrumentos } \\
\text { da compreensão }\end{array}$ & Biodiversidade & $\begin{array}{c}\text { Cegueira Paradigmática } \\
\text { Ensino das Incertezas }\end{array}$ \\
\hline $\begin{array}{c}\text { Aprender a Fazer: para poder agir sobre o meio } \\
\text { envolvente }\end{array}$ & Tecnologia & Conhecimento Pertinente \\
\hline $\begin{array}{c}\text { Aprender a Viver Juntos: fim de participar e } \\
\text { cooperar com os outros em todas as atividades } \\
\text { humanas }\end{array}$ & $\begin{array}{c}\text { Desenvolvimento } \\
\text { Sustentável }\end{array}$ & $\begin{array}{c}\text { Identidade Terrena } \\
\text { Ensino da Condição Humana }\end{array}$ \\
\hline $\begin{array}{c}\text { Aprender a Ser: via essencial que integra os três } \\
\text { precedentes }\end{array}$ & Ética & $\begin{array}{c}\text { Ensino da Compreensão Humana } \\
\text { Ética do Gênero Humano }\end{array}$ \\
\hline Aprender a Sentir & Humanização & $\begin{array}{c}\text { Ética do Gênero Humano } \\
\text { Ensino da Condição Humana }\end{array}$ \\
\hline
\end{tabular}

A Geologia exerce duplo papel formativo, como ciência experimental e como ciência histórica (Carneiro et al. 2004), mas no Brasil os alunos que completam a educação básica não dispõem de cultura geológica elementar nem conseguem aproximar-se de uma visão razoável sobre como a Terra funciona, tal como seria desejável (Pedrinaci 2002).

Nesse contexto, a questão da formação do professor assume fundamental importância, exigindo soluções inovadoras e novas abordagens que fundamentem os cursos preparatórios. Sem menosprezar outras áreas, parece urgente o ensino de saberes de ciência nos primeiros anos no ensino fundamental, visando atingir resultados significativos futuros nos demais níveis de ensino do país, haja vista a avaliação do PISA que apontara deficiências no tempo presente. O PISA não se preocupa em descobrir se os estudantes são capazes, por eles mesmos, de empreender investigações científicas, mas se a experiência adquirida na escola culmina

“(...) no entendimento dos processos científicos e na habilidade para aplicar os conceitos científicos que o tornariam capazes de tomar decisões sobre o mundo natural e as mudanças nele ocorridas em virtude da atividade humana" (OECD 2000, p.77).

No ensino fundamental, o mais importante é suscitar a curiosidade dos alunos em relação à natureza (Carneiro et al. 2004). Delors (1999;251) afirma que a curiosidade é comum na criança, entretanto muitas vezes os sistemas educacionais a tolhem. "Isso deve mudar", diz o autor; Pavão (2008) alerta ser preciso iniciar cedo, pois o interesse em ciências tem origem na infância: "este é um processo que pode ser iniciado muito cedo, desde os primeiros anos de escolaridade" (Pavão 2008, p. 203). O ensino de ciências apresenta peculiaridades e características específicas; no primeiro ciclo do ensino fundamental, prioriza-se o processo de alfabetização relegando-se a segundo plano as demais áreas do conhecimento. A aprendizagem de duas linguagens, Língua Portuguesa e Matemática depende da atuação polivalente do professor, que precisa trabalhar com todas as disciplinas. Teixeira (2013) assinala que a ideia de alfabetização científica deva estar "atrelada à alfabetização na própria língua":

Esta última alfabetização não estaria completa, não atingiria um grau maior de amplitude sem a primeira. Por conseguinte, o ensino de ciências seria concebido (com elaboração de propostas e condições de efetivação) no âmbito das necessidades educacionais do país, tendo por norte as contribuições que a alfabetização, em princípio, traria para a formação de indivíduos (Teixeira 2013:806).

Programas de inclusão digital concederam laboratórios de informática e acesso à internet à maioria das escolas públicas brasileiras, mas faltam cursos de preparação dos professores para a nova realidade (Barbosa 2013), o que dificulta a renovação do ensinopor meio do uso educacional do computador (Carneiro et al. 2005, 2007), ao permitir que "o aluno sintetize, organize e reestruture a informação", além de controlar "o tempo, espaço e velocidade de sua aprendizagem" (Carneiro et al. 2007).

Barbosa (2013) assinala que a designação "novas tecnologias de informação" ou "novas tecnologias de informação e comunicação", que podem ser referidas com a sigla TIC ou NTIC, são modos habituais de se reportar à Internet, sem no entanto se limitar a ela. Os termos englobam "recursos computacionais de todos os gêneros que possam ser aproveitados na educação". O autor estabelece algumas relações significativas entre TICs e ensino-aprendizagem:

Usaremos o termo TIC para designar a 
tecnologia educacional vinculada ao uso de computadores ou recursos computacionais com possibilidade de aproveitamento tanto dentro quanto fora da escola, com ou sem supervisão de um professor. (...) A ideia comum de que caberia ao professor apenas $o$ ato de ensinar, e ao aluno apenas o ato de aprender, levou a uma série de desafios e dificuldades na inserção das TICs na escola. Uma TIC na educação pode tanto ser uma tecnologia de ensino quanto uma tecnologia de aprendizagem, dependendo do uso que se faça dela. Entretanto, não necessariamente será de ensino se estiver nas mãos do professor, nem tampouco será de aprendizagem se estiver nas mãos do aluno.

A integração de computadores na escola é percebida sob a perspectiva de uma dinâmica de interação. Considerado um instrumento de mediação entre sujeitos, o computador oferece recursos que estimulam a investigação e proporcionam certas condições para interpretação e análise, além de paradas e retornos condizentes com o ritmo do aluno. "As simulações computacionais possibilitam o entendimento de sistemas complexos para estudantes de idades, habilidades e níveis de aprendizagem variados" (Pavão 2008:138). Estimular e orientar alunos no processo de construção do conhecimento é papel do professor, para que cada um se sinta confortável para fazer as próprias descobertas e desenvolver capacidades como observação, pensamento, criação, comunicação.

\section{As TICs e as novas interfaces}

Os avanços tecnológicos que demandam mudanças radicais em tempo record exigem em contrapartida novas formas de pensar e entender e de se situar no mundo. A utilização das TICs, segundo Papert (2008, p.151) propagou-se para mundos de aplicação mais amplos; a ideia de usá-las na educação estava fadada a surgir. Educar com emprego de TICs envolve "uma nova cultura educacional que exige decisão política, inovação na gestão, garantia de financiamento, capacitação constante e competência técnica" (Neves 2009). Ofertar um ensino de qualidade efetivo pressupõe ações que transponham o mero aparelhamento tecnológico das escolas. Neste contexto, como afirma Barbero (2011):

Não é demais recordar aqui que com o computador não estamos diante da tradicional relação de um corpo e uma máquina, relação dedicada à economia de força muscular ou da repetição infinita da mesma tarefa, mas diante de uma combinação de cérebro e informação incompreensível fora da inovação radical que introduziu as novas figuras da razão que possibilitaram a racionalidade técnica (Barbero 2011:25).

Os computadores e seu caráter interativo podem colaborar para aprendizagem significativa, além de criar ambiente construtivo ao levar em conta os conhecimentos prévios dos alunos, seus interesses, suas expectativas; os computadores podem criar oportunidade para novas descobertas. Da mesma forma, segundo Papert (2000:169) “...os computadores não apenas melhorariam a aprendizagem escolar, mas apoiariam formas diferentes de pensar e aprender". Apresenta-se, portanto, ao sistema educativo um grande desafio: "assumir a tecnologia como uma realidade concebida por intermédio do sistema simbólico da cultura em seu conjunto, abandonando a concepção utilitária da tecnologia como mero instrumento" (Navarro 2011:69).

Neste cenário não se confere à tecnologia o lugar de protagonista. Este principal papel é dado ao aluno visando o seu aprimoramento e sua adaptação ao novo; ele deve, pois, utilizar-se de todos os recursos que a tecnologia lhe oferece na escola e fora dela. Em relação às mudanças previstas, Navarro (2011) alerta que:

“(...) os ambientes que conhecemos hoje poderão sofrer modificações substanciais as quais deveremos de novo nos adaptar cognitivamente, por exemplo, diante de um hipotético cenário de uma nova geração de interfaces" (Navarro 2011:75)

Para tanto é preciso atualizar-se constantemente, estar sempre atento às exigências demandadas pela sociedade da informação.

\section{Considerações Finais}

O ideário educacional brasileiro transpõe a dimensão da educação sonhada tentando alcançar pelo menos a educação desejada possível, frente às dificuldades que emergem e se avolumam de norte a sul do país. Assim se apresenta o Brasil de poucos, os que se fazem conformados, porque o Brasil de muitos vive sempre à espera de uma hora 
que nunca vem.

Reconhecemos a legitimidade do papel do professor que, embora desvalorizado, altaneiro, sustenta a sua bandeira. Idealizamos o ensino de Ciências e, por conseguinte, das Geociências, como uma persistente reelaboração de propostas e geração de condições que atendam às necessidades educacionais do país e à formação de cidadãos cultos e capazes de discernir de modo adequado frente às escolhas que a vida por certo se lhes apresentará. Sabemos ainda que o desenvolvimento de um povo corresponde ao que lhe foi despendido em educação e que vivemos hoje em um país globalizado, portanto com oportunidades e responsabilidades de dimensões globais. É preciso fazer a hora porque este novo tempo, de velocidade máxima, não espera, mas requer ações imediatas que respondam a inúmeros desafios simultâneos. Portanto, mudar o quadro da educação do país é uma questão de soberania, uma exigência do tempo, da hora, do espaço agora global. A educação é direito de todo sem distinção, devendo ser igualitária; fazê-la real é responsabilidade daqueles que democraticamente nos representam e respeitam nossos interesses coletivos.

\section{Agradecimentos}

Os autores agradecem ao Prof. Dr. Jorge Kazuo Yamamoto pelas sugestões para aprimoramento do manuscrito.

\section{Referências}

American Association for the Advancement of Science. 1989. Science for all Americans. Washington, D. C.: AAAS.

Barbeiro J.M. 2011. Desafios da tecnicidade ao sistema educativo. In.: Filé V. org. 2011. Escola e tecnologia: máquinas, sujeitos e conexões culturais. Rio de Janeiro: Rovelle. (Col. (com) textos da educação. Escola e cotidiano, 7).

Barbosa R. 2013. Projeto Geo-Escola: Geociências para uma escola inovadora. Campinas: Inst. Geoc. Unicamp. (Tese Dout. PEHCT). URL: http:/www.bibliotecadigital.unicamp. br/document/? code $=000920387$. Acesso 30.06.2014.

Barreto R.G., Guimarães G.C., Magalhães L.K.C.de, Leher E.M.T. 2006. As tecnologias da informação e da comunicação na formação de professores. Rev. Bras. Educ., 11(31):31-42. URL: http:// www.scielo.br/pdf/rbedu/v11n31/a04v11n31. pdf. Acesso 21.10.2014.

Carneiro C.D.R., Toledo M.C.M. de, Almeida F.F.M. de. 2004. Dez motivos para a inclusão de temas de Geologia na Educação Básica. Rev. Bras. Geoc. 34(4):553-560.

Debald F.R.B. 2012. A formação dos professores e sua relação com as Tecnologias da Informação e Comunicação. Foz do Iguaçu, Rev. Pleiade, 3(6):135146. URL: http://www.uniamerica.br/site/revista/index.php/pleiade/ article/view/23/18. Acesso 20.10.2014.

Delors J. 1996. Education for tomorrow. UNESCO Courier, Abril 1996, 49(4):6.

Delors J. org. 2005. A educação para o século XXI: questões e perspectivas. Porto Alegre: Artmed.

Delors, J. 1999.Educação: um tesouro a descobrir.São Paulo, Cortez. Brasília,MEC/UNESCO.

Fialho F.A.P. 2002a. Escola do Futuro: em busca da razão de ser. Revista@prender.

Fialho F.A.P. 2002b. Curso de Capacitação em Ensino a Distância - EAD Francisco Antonio Pereira Fialho, Dr. Eng. Professor do Programa de Pós Graduação em Engenharia e Gestão. Florianópolis, UFSC. (Curso Pós-Grad. Eng. Prod .). URL: http://slideplayer. com.br/slide/1658485/. Acesso 20.10.2014.

Fracalanza H., Amaral I.A.do, Gouveia M.S.F. 1986. O ensino de ciências no primeiro grau. São Paulo: Atual. Maia M.C. 2003. O Uso da Tecnologia de Informação para a Educação a Distância no Ensino Superior. São Paulo, FGV - EAESP. 294p. (Tese Dout. curso de Pós-Graduação em Admin. Empresas FGV-EAESP, Área Conc. Prod. e Sist. Informação). URL: http://bibliotecadigital.fgv.br/dspace/bitstream/ handle/10438/2463/74603.pdf? sequence $=2$. Acesso 20.10.2014.

Martins J.R.S., Carneiro C.D.R. 2012. Plataforma continental jurídica, recursos do pré-sal e ensino de Geociências. Campinas, Terra, 9(1):60109. URL: http://www.ige.unicamp.br/terrae/ V9/T_V9_A6.html. Acesso 20.08.2013.

Martins J.R.S., Carneiro C.D.R. 2014a. Massa crítica de professores e investigadores: importante contribuição à implementação de uma perspectiva curricular ao ensino de Geociências. Terræ Didatica, 10(3):. http://www.ige.unicamp.br/ terraedidatica/.

Martins J.R.S., Carneiro C.D.R. 2014b. Teaching and Learning in Geosciences for Citizenship: from the margins of knowledge to the central tasks of forming teachers. Athens: ATINER'S Conference Paper Series, No: EDU2014-1249. URL: www. atiner.gr/papers/EDU2014-1249.pdf. Acesso 16.09.2014.

Martins J.R.S., Gonçalves P.W., Carneiro C.D.R. 2011. O ciclo hidrológico como chave analítica interpretativa de um material didático em Geologia. Bauru: Ciência E Educação. 17(2):365-382. URL: http://redalyc.uaemex.mx/src/inicio/ ArtPdfRed.jsp?iCve $=251019454008$. Acesso 
10.04.2012.

Menegat R., Carraro C.C. 2009. Manual para saber porque o Guaíba é um lago : análise integrada de geologia, geomorfologia, hidrologia, estratigrafia e história da ciência. Porto Alegre: Armazém Digital. 113p.

Moreira M.A., Masini E.F.S. 1982. Aprendizagem Significativa. A teoria de David Ausubel. São Paulo, Moraes.

Morin E. 2001. Os sete saberes necessários à educação do futuro. 4. Ed. Trad. Catarina E.F. da Silva e Janne Sawaya, rev. técn. Edgard A. Carvalho. São Paulo: Cortez, Brasília: UNESCO. 118.

Mortimer E.F., Scott P., El-Hani C.N. 2011. Bases teóricas e epistemológicas da abordagem dos perfis conceituais. TED: Tecné, Episteme y Didaxis, 30:111-125. URL: revistas.pedagogica.edu.co/ index.php/TED/article/download/1102/1109. Acesso 20.10.2014.

Mortimer, E. F.Linguagem e formação de conceitos no ensino de Ciências.Belo Horizonte: UFMG, 2000.

Navarro, Maria G. A natureza da ação nos cenários virtuais e o desafio de educar para uma inteligência coletiva. In.: Filé V. org. 2011. Escola e tecnologia: máquinas, sujeitos e conexões culturais. Rio de Janeiro: Rovelle. (Col. (com) textos da educação. Escola e cotidiano, 7).

Neves C.M.C. 2009. Educar com TICs: o caminho entre a excepcionalidade e a invisibilidade. Rio de Janeiro, Rev. Téc. Senac, 35(3):17-27. TRL: www.senac.br/BTS/353/artigo-02.pdf. Acesso 2.07.2014.

Organisation for Economic Co-Operation and Development OECD. 1999. Measuring students kno- wledge and skills: a new framework for assessment. Paris: OECD.

Papert S. 2008. A máquina das crianças: repensando a escola na era da informática. Trad. Sandra Costa. ed. rev. Porto Alegre. Artmed.

Pavão A.C., Freitas D. (Org.). 2008. Quanta ciência há no ensino de ciências. São Carlos: Edufscar.

Pedrinaci E. 2002. La Geología en el bachillerato: un análisis del nuevo curriculum. Rev. de la Enseñanza de las Ciencias de la Tierra. 10(2):125-133.

Santos E. 2006. Articulação de saberes na EAD on-line. Por uma rede interdisciplinar e interativa em ambientes virtuais, M. (org) Educação on-line: práticas legislação, formação corporativa. São Paulo: Loyola.

Sgarbi G.N.C. 2001. Geologia Introdutória: base para o novo conhecimento. Rev. Ci. Humanas, 1(2):153-162.

Signoretti V.V., Carneiro C.D.R. 2013. As TICs no ensino de Geociências: por uma inovação na interface entre ensinar e aprender. In: Encontro Nacional de Práticas de Ensino em Geografia, 12, João Pessoa, 2013. Anais..., João Pessoa, ENPEG.

Tardif M. 2002. Saberes docentes e formação profissional. Petrópolis, RJ: Vozes.

Teixeira F.M. 2013. Alfabetização científica: questões para reflexão. Bauru, Ciênc. Educ., 19(4):795809. URL: www.scielo.br/pdf/ciedu/v19n4/ v19n4a02.pdf. Acesso 29.10.2014. 